Pacific Journal of Mathematics

ON THE MAXIMUM AND MINIMUM OF PARTIAL SUMS OF 


\section{ON THE MAXIMUM AND MINIMUM OF PARTIAL SUMS OF RANDOM VARIABLES}

\section{Peggy Tang Strait}

Let $X_{1}, X_{2}, \cdots, X_{n}$ be independent identically distributed random variable with $S_{k}=X_{1}+X_{2}+\cdots+X_{k}$ and $S_{k}^{+}=$ $\max \left[0, S_{k}\right]$. We shall derive formulas for the computation of $E\left[\min _{1 \leqq k \leqq n} S_{k}^{+}\right], \quad E\left[\max _{1 \leqq k \leqq n} S_{k}\right]$, and $E\left[\min _{1 \leqq k \leqq n} S_{k}\right]$. The formulas are then applied to the case of standard normal random variables.

2. Notation, definitions, and preliminary lemmas. Let $x=$ $\left(x_{1}, \cdots, x_{n}\right)$ be a vector with real components and $-x=\left(-x_{1}, \cdots\right.$, $\left.-x_{n}\right)$. In some instances we shall also assume that the components $x_{i}, i=1,2, \cdots, n$ are rationally independent. (For rational $r_{i}, r_{1} x_{1}+$ $r_{2} x_{2}+\cdots+r_{n} x_{n}=0$ if and only if each $r_{i}=0$.) Let $x_{k+n}=x_{k}$, and $x(k)=\left(x_{k}, x_{k+1}, \cdots, x_{k+n-1}\right), k=1,2, \cdots, n$. Let $s_{k}=x_{1}+x_{2}+\cdots+x_{k}$. Call the polygon connecting the points $(0,0),\left(1, s_{1}\right), \cdots,\left(k, s_{k}\right), \cdots$, $\left(n, s_{n}\right)$ the sum polygon of the vector $x$, and the line connecting $(0,0)$ with $\left(n, s_{n}\right)$ the chord of the sum polygon. The sum polygon for the cyclically permuted vector $x(k)$ is defined the same way.

F. Spitzer proved in [2] (see especially page 325, lines 8-12) the following lemma.

Lemma 1. Let $x=\left(x_{1}, \cdots, x_{n}\right)$ be a vector such that the components $x_{i}, i=1, \cdots, n$, are rationally independent. Consider the sum polygons of the $n$ cyclic permutations of $x$ and prescribe an integer $r$ between 0 and $n-1$. The sum polygon of exactly one of the cyclic permutations of $x$ has the property that exactly $r$ of its vertices lie strictly above its chord.

We adopt the following notations and definitions. For any real $a$,

$$
a^{+}=\max [0, a], \quad a^{-}=\min [0, a]
$$

$\sigma$ is the permutation on $n$ symbols, so that

$$
\sigma x=\left(\begin{array}{cccc}
1 & 2 & \cdots & n \\
\sigma_{1} \sigma_{2} & \cdots & \sigma_{n}
\end{array}\right) x=\left(x_{\sigma_{1}}, x_{\sigma_{2}}, \cdots, x_{\sigma_{n}}\right) .
$$

We write 


$$
\begin{aligned}
s_{k}(\sigma x) & =x_{\sigma_{1}}+x_{\sigma_{2}} \cdots+x_{\sigma_{k}} \\
S(\sigma x) & =\max _{1 \leqq k \leqq n} s_{k}^{+}(\sigma x)=\max _{1 \leqq k \leqq n}\left(\sum_{i=1}^{k} x_{\sigma_{i}}\right)^{+} \\
S^{*}(\sigma x) & =\min _{1 \leqq k \leqq n} s_{k}^{+}(\sigma x)=\min _{1 \leqq k \leqq n}\left(\sum_{i=1}^{k} x_{\sigma_{i}}\right)^{+} .
\end{aligned}
$$

$\tau$ is the permutation on $n$ symbols represented as a product of cycles, including the one-cycles, and with each index contained in exactly one cycle. For example, with $n=7$, we could have

$$
\tau=(14)(2)(3756) \text {. }
$$

For each $x$ and $\tau$ we define $T(\tau x)$ as follows. Suppose $\tau$ is the example given (2.4) above, then

$$
T(\tau x)=\left(x_{1}+x_{4}\right)^{+}+x_{2}^{+}+\left(x_{3}+x_{7}+x_{5}+x_{6}\right)^{+} .
$$

In formal notations we write

$$
\tau=\left(\alpha_{1}(\tau)\right)\left(\alpha_{2}(\tau)\right) \cdots\left(\alpha_{n(\tau)}(\tau)\right)
$$

where the $\alpha_{i}(\tau), i=1,2, \cdots, n(\tau)$, are disjoint sets of integers whose union is the set $[1,2, \cdots, n]$. Then $T(\tau x)$ is defined as

$$
T(\tau x)=\sum_{i=1}^{n(\tau)}\left(\sum_{k \in \alpha_{i}(\tau)} x_{k}\right)^{+} .
$$

If $X_{1}, X_{2}, \cdots, X_{n}$ are random variables and we write $X=\left(X_{1}, \cdots, X_{n}\right)$ then it is understood that

$$
\begin{aligned}
S_{k} & =X_{1}+X_{2}+\cdots+X_{k} \\
S_{k}^{+} & =\max \left[0, S_{k}\right] \\
S(\sigma X) & =\max _{1 \leqq k \leqq n}\left(\sum_{i=1}^{k} X_{\sigma_{i}}\right)^{+} \\
T(\tau X) & =\sum_{i=1}^{n(\tau)}\left(\sum_{k \in \alpha_{i}} X_{k}\right)^{+} .
\end{aligned}
$$

The following lemma is also due to F. Spitzer [2].

Lemma 2. Let $X_{1}, X_{2}, \cdots, X_{n}$ be independent identically distributed random variables. Then,

$$
\begin{aligned}
E\left[\max _{1 \leqq k \leqq n} S_{k}^{+}\right] & =\frac{1}{n !} \sum_{\sigma} E[S(\sigma X)] \\
& =\frac{1}{n !} \sum_{\tau} E[T(\tau X)]=\sum_{k=1}^{n} \frac{1}{k} E\left[S_{k}^{+}\right],
\end{aligned}
$$

where it is understood that the second sum is over equivalence classes 
of $\tau$ with the definition that if $\tau=\left(\alpha_{1}(\tau)\right)\left(\alpha_{2}(\tau)\right) \cdots\left(\alpha_{n(\tau)}(\tau)\right)$ and $\tau^{\prime}=\left(\alpha_{1}^{\prime}\left(\tau^{\prime}\right)\right)\left(\alpha_{2}^{\prime}\left(\tau^{\prime}\right)\right) \cdots\left(\alpha_{n\left(\tau^{\prime}\right)}^{\prime}\left(\tau^{\prime}\right)\right)$ then $\tau \sim \tau^{\prime}$ if $n(\tau)=n\left(\tau^{\prime}\right)$ and for each $i$ there is exactly one $j$ and for each $j$ there is exactly one $i$ for which $\alpha_{i}(\tau)$ is some cyclic permutation of $\alpha_{j}^{\prime}\left(\tau^{\prime}\right)$.

F. Spitzer proved Lemma 2 by using Lemma 1 and the following fundamental principle. Let $X=\left(X_{1}, \cdots, X_{n}\right)$ be an $n$-dimensional vector valued random variable, and let $\mu(x)=\mu\left(x_{1}, \cdots, x_{n}\right)$ be its probability measure (defined on Euclidean $n$-space $E_{n}$ ). Suppose that $X$ has the property that $\mu(x)=\mu(g x)$ for every element $g$ of a group $G$ of order $h$ of transformations of $E_{n}$ into itself. Let $f(x)=$ $f\left(x_{1}, \cdots, x_{n}\right)$ be a $\mu$-integrable complex valued function on $E_{n}$. Then the expected value of $f(X)$ is

$$
E f(X)=\int f(x) d \mu(x)=\int \bar{f}(x) d \mu(x)
$$

where

$$
\bar{f}(x)=\frac{1}{h} \sum_{g \in G} f(g x) .
$$

To make use of this fundamental principle and Lemmas 1 and 2 in the proof of our main results we now define the permutation $\mu$ (not the measure $\mu$ above) as follows. (It is similar but not identical to the permutation $\tau$ defined above.) Let $\mu$ be represented as a product of cycles, including the one cycle, with each index $1, \cdots, n$ contained in exactly one cycle, and beginning always with a one cycle. For example, with $n=8$, we could have

$$
\mu=(2)(14)(8)(3756) \text {. }
$$

For each $x$ and $\mu$ we define $U(\mu x)$ as follows. Suppose $\mu$ is the example given in (2.11) above, then

$$
U(\mu x)=\left(x_{1}+x_{4}\right)^{+}+\left(x_{8}\right)^{+}+\left(x_{3}+x_{7}+x_{5}+x_{6}\right)^{+} .
$$

Observe that $x_{2}$, the single element in the beginning one cycle, is not included in the sum. In formal notation, let

$$
\mu=\left(\beta_{1}(\mu)\right)\left(\beta_{2}(\mu)\right) \cdots\left(\beta_{n(\mu)}(\mu)\right)
$$

where the $\beta_{i}(\mu), i=1, \cdots, n(\mu)$, are disjoint sets of integers whose union is the set $[1,2, \cdots, n]$, and $\left.\beta_{1}(\mu)\right)$ consists of exactly one of the integers $1, \cdots, n$. Then,

$$
U(\mu x)=\sum_{i=2}^{n(\mu)}\left(\sum_{k \in \beta_{i}(\mu)} x_{k}\right)^{+} .
$$

We next define for each fixed vector $x$ a map $\mu_{x}(\sigma)$ as follows. Given 


$$
\sigma=\left(\begin{array}{llll}
1 & 2 & \cdots & n \\
i_{1} i_{2} & \cdots & i_{n}
\end{array}\right)
$$

consider the sum polygon through the points $\left(1, x_{i_{1}}\right),\left(2, x_{i_{1}}+x_{i_{2}}\right), \cdots$, $\left(k, x_{i_{1}}+\cdots+x_{i_{k}}\right), \cdots,\left(n, s_{n}\right)$. Define the highest concave majorant of the sum polygon as that unique concave polygon which goes through $\left(1, x_{i_{1}}\right)$ and $\left(n, s_{n}\right)$ in such a way that all its vertices are also vertices of the sum polygon and that it always lies below or coincides with the sum polygon. Suppose now that the highest concave majorant constructed for the permutation $\sigma$ has the vertices $\left(1, x_{i_{1}}\right)$, $\left(k_{1}, x_{i_{1}}+\cdots+x_{i_{k_{1}}}\right), \cdots,\left(k_{\nu}, x_{i_{1}}+\cdots+x_{i_{k_{\nu}}}\right),\left(n, s_{n}\right) \quad$ where $1<k_{1}<$ $\cdots<k_{\nu}<n$. Then we define

$$
\mu_{x}(\sigma)=\left(i_{1}\right)\left(i_{2}, \cdots, i_{k_{1}}\right)\left(i_{k_{1}+1}, \cdots, i_{k_{2}}\right) \cdots\left(i_{k_{2}+1}, \cdots, i_{n}\right) .
$$

Now observe that

$$
\begin{aligned}
S^{*}(\sigma x) & =\min _{1 \leqq k \leqq n}\left(\sum_{j=1}^{k} x_{i_{j}}\right)^{+}=\left[s_{n}-U\left(\mu_{x}(\sigma) x\right)\right]^{+} \\
& =S(\sigma(-x))+s_{n}-U\left(\mu_{x}(\sigma) x\right)
\end{aligned}
$$

or

$$
-U\left(\mu_{x}(\sigma) x\right)=S^{*}(\sigma x)-S(\sigma(-x))-s_{n} .
$$

Going in the other direction, we define for each fixed vector $x$ with rationally independent components, a map $\sigma_{x}(\mu)$ as follows. Suppose that

$$
\begin{aligned}
\mu & =\left(\beta_{1}(\mu)\right)\left(\beta_{2}(\mu)\right) \cdots\left(\beta_{n(\mu)}(\mu)\right) \\
& =\left(j_{1}\right)\left(\beta_{2}(\mu)\right) \cdots\left(\beta_{n(\mu)}(\mu)\right) .
\end{aligned}
$$

(See the paragraph following equation (2.12) for the definition of $\mu$, and notice in particular that the leading cycle $\beta_{1}(\mu)$ must be a one cycle.) Rewrite each set $\beta_{2}(\mu), \beta_{3}(\mu), \cdots, \beta_{n(\mu)}(\mu)$ as follows. Suppose $\beta_{k}(\mu)=(3,6,9,2)$. Consider the sum polygon of the vector $\left(x_{3}, x_{6}\right.$, $\left.x_{9}, x_{2}\right)$. By Lemma 1 there is a unique cyclic permutation of $\left(x_{3}, x_{6}, x_{9}, x_{2}\right)$ such that all of the vertices of the sum polygon lie strictly above its chord. Suppose that unique permutation is $\left(x_{9}, x_{2}, x_{3}, x_{6}\right)$ then rewrite $\beta_{k}(\mu)$ as $(9,2,3,6)$ and call it $\beta_{k}^{\prime}(\mu)$. Define $\mu^{\prime}$ as

$$
\begin{aligned}
\mu^{\prime} & =\left(\beta_{1}(\mu)\right)\left(\beta _ { 2 } ^ { \prime } ( \mu ) \cdots \left(\beta_{n(\mu)}^{\prime}(\mu)\right.\right. \\
& =\left(j_{1}\right)\left(\beta_{2}^{\prime}(\mu)\right) \cdots\left(\beta_{n(\mu)}^{\prime}(\mu)\right) .
\end{aligned}
$$

Observe that

$$
U(\mu x)=U\left(\mu^{\prime} x\right)
$$


Now consider the vector

(2.22) $y=\left(y_{2}, y_{3}, \cdots, y_{n}\right)=\left(\sum_{k \in \beta_{2}^{\prime}(\mu)} x_{k}, \sum_{k \in \beta_{3}^{\prime}(\mu)} x_{k}, \cdots, \sum_{k \in \beta_{n(\mu)}^{\prime}(\mu)} x_{k}\right) \cdot$

There is a unique permutation of the components of $y$, say

(2.23) $y^{\prime}=\left(y_{2}^{\prime}, y_{3}^{\prime}, \cdots, y_{n}^{\prime}\right)=\left(\sum_{k \in \beta_{2}^{\prime \prime}(\mu)} x_{k}, \sum_{k \in \beta_{3}^{\prime \prime}(\mu)} x_{k}, \cdots, \sum_{\left.k \in \beta_{n}^{\prime}(\mu)^{\prime \mu}\right)} x_{k}\right)$

so that

$$
\frac{\sum_{k \in \beta_{2}^{\prime \prime}(\mu)} x_{k}}{\sum_{k \in \beta_{2}^{\prime \prime}(\mu)} 1}<\frac{\sum_{k \in \beta_{3}^{\prime \prime}(\mu)} x_{k}}{\sum_{k \in \beta_{3}^{\prime \prime}(\mu)} 1}<\cdots<\frac{\sum_{k \in \beta_{n}^{\prime \prime}(\mu)} x_{k}(\mu)}{\sum_{k \in \beta_{n}^{\prime}(\mu)} 1}
$$

Now define

$$
\mu^{\prime \prime}=\left(j_{1}\right)\left(\beta_{2}^{\prime \prime}(\mu)\right)\left(\beta_{3}^{\prime \prime}(\mu)\right) \cdots\left(\beta_{n(\mu)}^{\prime \prime}(\mu)\right)
$$

Observe that

$$
U\left(\mu^{\prime \prime} x\right)=U\left(\mu^{\prime} x\right)=U(\mu x)
$$

Suppose $\mu^{\prime \prime}$ can be written as

$$
\mu^{\prime \prime}=\left(j_{1}\right)\left(j_{2}, \cdots, j_{h_{1}}\right)\left(j_{h_{1}+1}, \cdots, j_{h_{2}}\right) \cdots\left(j_{h_{\nu}+1}, \cdots, j_{n}\right)
$$

we then define

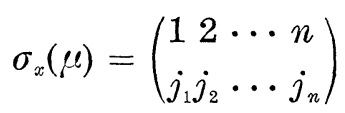

observe that with respect to the sum polygon through the points $\left(1, x_{j_{1}}\right),\left(2, x_{j_{1}}+x_{j_{2}}\right), \cdots,\left(k, x_{j_{1}}+\cdots+x_{j_{k}}\right), \cdots,\left(n, s_{n}\right)$ the vertices of the highest concave majorant are at the points $\left(1, x_{j_{1}}\right),\left(h_{1}, x_{j_{1}}+\right.$ $\left.\cdots+x_{j_{h_{1}}}\right),\left(h_{2}, x_{j_{1}}+\cdots+x_{j_{h_{2}}}\right), \cdots,\left(h_{j_{\nu}}, x_{j_{1}}+\cdots+x_{j_{h_{\nu}}}\right),\left(n, s_{n}\right)$. Thus

$$
\mu_{x}\left(\sigma_{x}(\mu)\right)=\mu^{\prime \prime} \text {. }
$$

Now use equations (2.17), (2.29), and (2.26) to obtain

$$
\begin{aligned}
S^{*}\left(\sigma_{x}(\mu) x\right) & =S\left(\sigma_{x}(\mu)(-x)\right)+s_{n}-U\left(\mu_{x}\left(\sigma_{x}(\mu)\right) x\right) \\
& =S\left(\sigma_{x}(\mu)(-x)\right)+s_{n}-U\left(\mu^{\prime \prime} x\right) \\
& =S\left(\sigma_{x}(\mu)(-x)\right)+s_{n}-U(\mu x)
\end{aligned}
$$

which is equivalent to

$$
-U(\mu x)=S^{*}\left(\sigma_{x}(\mu) x\right)-S\left(\sigma_{x}(\mu)(-x)\right)-s_{n} .
$$


Now consider the sets $[-U(\mu x)]$ and $\left[S^{*}(\sigma x)-S(\sigma(-x))-s_{n}\right]$ generated by letting $\sigma$ and $\tau$ run through all permutations. We have shown above that for vectors $x$ with rationally independent components, the maps $\sigma_{x}(\mu)$ and $\mu_{x}(\sigma)$ define a one-to-one map of the set $[-U(\mu x)]$ onto the set $\left[S^{*}(\sigma x)-S\left(\sigma(-x)-s_{n}\right]\right.$. Furthermore, since the set $x$ of vectors in $E_{n}$ with rationally independent component is dense in $E_{n}$ and the functions $S(\sigma x)$ and $U(\mu x)$ are continuous functions of $x$, we have proved the following lemma.

LEMmA 3. For an arbitrary fixed vector $x=\left(x_{1}, \cdots, x_{n}\right)$ the sets $[-U(\mu x)]$ and $\left[S^{*}(\sigma x)-S(\sigma(-x))-s_{n}\right]$ which are generated by letting $\sigma$ and $\tau$ run through all permutations are identical sets.

\section{The main theorems.}

Theorem 1. Let $X_{1}, X_{2}, \cdots, X_{n}$ be independent, identically distributed random variables.

$$
\begin{aligned}
E\left[\min _{1 \leqq k \leqq n} S_{k}^{+}\right] & =E\left(S_{n}\right)+\sum_{k=1}^{n} \frac{1}{k} E\left[\left(-S_{k}\right)^{+}\right]-\sum_{k=1}^{n-1} \frac{1}{k} E\left(S_{k}^{+}\right) \\
& =E\left(S_{n}\right)+\frac{1}{n} E\left(S_{n}^{+}\right)-\sum_{k=1}^{n} \frac{1}{k} E\left(S_{k}\right) .
\end{aligned}
$$

Proof. Using the fundamental principle (2.10) we may write

$$
E\left[\min _{1 \leqq k \leqq n} S_{k}^{+}\right]=\frac{1}{n !} \sum_{\sigma} E\left[S^{*}(\sigma X)\right]
$$

and applying (2.17) to the term on the right we have

$$
\begin{aligned}
E\left[\min _{1 \leqq k \leqq n} S_{k}^{+}\right]= & \frac{1}{n !} \sum_{\sigma} E\left[S(\sigma(-X))+S_{n}-U\left(\mu_{x}(\sigma) X\right)\right] \\
= & \frac{1}{n !} \sum_{\sigma} E[S(\sigma(-X))]+E\left(S_{n}\right) \\
& -\frac{1}{n !} \sum_{\sigma} E\left[U\left(\mu_{x}(\sigma) X\right)\right] .
\end{aligned}
$$

Now apply Lemma 3 to obtain

$$
E\left[\min _{1 \leqq k \leqq n} S_{k}^{+}\right]=\frac{1}{n !} \sum_{\sigma} E[S(\sigma(-X))]+E\left(S_{n}\right)-\frac{1}{n !} \sum_{\mu} E[U(\mu X)]
$$

where it is understood that the second sum is over equivalence classes of $\mu$ with the definition that if

$$
\mu=\left(\beta_{1}(\mu)\right)\left(\beta_{2}(\mu)\right) \cdots\left(\beta_{n(\mu)}(\mu)\right)
$$


and

$$
\mu^{\prime}=\left(\beta_{1}^{\prime}\left(\mu^{\prime}\right)\right)\left(\beta_{2}^{\prime}\left(\mu^{\prime}\right)\right) \cdots\left(\beta_{n\left(\mu^{\prime}\right)}^{\prime}\left(\mu^{\prime}\right)\right)
$$

then $\mu \sim \mu^{\prime}$ if $n(\mu)=n\left(\mu^{\prime}\right), \beta_{1}(\mu)=\beta_{1}^{\prime}\left(\mu^{\prime}\right)$ and for each $i$ there is exactly one $j$ and for each $j$ there is exactly one $i$ for which $\beta_{t}(\mu)$ is some cycle permutation of $\beta_{j}^{\prime}\left(\mu^{\prime}\right)$.

Let us consider the last term in equation (3.4). Define $X^{\prime}=\left(X_{2}, \cdots\right.$, $X_{n}$ ) and keep in mind that the random variables $X_{1}, X_{2}, \cdots, X_{n}$ are independent and identically distributed. It is then clear from our definition of $T(\tau x)$ and $U(\mu x)$ that

$$
\frac{1}{n !} \sum_{\mu} E[U(\mu X)]=\frac{1}{n !} \sum_{\tau} E\left[T\left(\tau X^{\prime}\right)\right] \text {. }
$$

Now apply Lemma 2 to equations (3.4) and (3.5) to obtain

$$
E\left[\min _{1 \leqq k \leqq n} S_{k}^{+}\right]=\sum_{k=1}^{n} \frac{1}{k} E\left[\left(-S_{k}\right)^{+}\right]+E\left(S_{n}\right)-\sum_{k=1}^{n-1} \frac{1}{k} E\left[S_{k}^{+}\right]
$$

which is the first part of equation (3.1). Then, using the fact that $E\left[\left(-S_{k}\right)^{+}\right]-E\left(S_{k}^{+}\right)=-E\left(S_{k}\right)$, we obtain the second part of equation (3.1) as follows.

$$
\begin{aligned}
& E\left(S_{n}\right)+\sum_{k=1}^{n} \frac{1}{k} E\left[\left(-S_{k}\right)^{+}\right]-\sum_{k=1}^{n-1} \frac{1}{k} E\left(S_{k}^{+}\right) \\
& =E\left(S_{n}\right)+\sum_{k=1}^{n} \frac{1}{k} E\left[\left(-S_{k}\right)^{+}\right]-\sum_{k=1}^{n} \frac{1}{k} E\left(S_{k}^{+}\right)+\frac{1}{n} E\left(S_{n}^{+}\right) \\
& =E\left(S_{n}\right)+\sum_{k=1}^{n} \frac{1}{k}\left\{E\left(-S_{k}\right)^{+}-E\left(S_{k}^{+}\right)\right\}+\frac{1}{n} E\left(S_{n}^{+}\right) \\
& =E\left(S_{n}\right)+\frac{1}{n} E\left(S_{n}^{+}\right)-\sum_{k=1}^{n} \frac{1}{k} E\left(S_{k}\right) .
\end{aligned}
$$

THEOREM 2.

$$
\begin{aligned}
E\left[\max _{1 \leqq k \leqq n} S_{k}\right] & =\sum_{k=1}^{n-1} \frac{1}{k} E\left[\left(-S_{k}\right)^{+}\right]+E\left(S_{n}\right) \\
& =E\left(S_{n}\right)+E\left[\max _{1 \leqq k \leqq n-1}\left(-S_{k}\right)^{+}\right] .
\end{aligned}
$$

Proof.

(3.8) $\max _{1 \leqq k \leqq n} S_{k}=\max _{1 \leqq k \leqq n} S_{k}^{+}+\max _{1 \leqq k \leqq n} S_{k}^{-}$, and $\max _{1 \leqq k \leqq n} S_{k}^{-}=-\min _{1 \leqq k \leqq n}\left(-S_{k}\right)^{+}$.

Therefore, 


$$
E\left[\max _{1 \leqq k \leqq n} S_{k}\right]=E\left[\max _{1 \leqq k \leqq n} S_{k}^{+}\right]-E\left[\min _{1 \leqq k \leqq n}\left(-S_{k}\right)^{+}\right] .
$$

From Theorem 1, we have

$$
\begin{aligned}
& E\left[\min _{1 \leqq k \leqq n}\left(-S_{k}\right)^{+}\right] \\
& \quad=E\left(-S_{n}\right)+\sum_{k=1}^{n} \frac{1}{k} E\left[\left(S_{k}\right)^{+}\right]-\sum_{k=1}^{n-1} \frac{1}{k} E\left[\left(-S_{k}\right)^{+}\right] .
\end{aligned}
$$

From Lemma 2, we have

$$
E\left[\max _{1 \leqq k \leqq n} S_{k}^{+}\right]=\sum_{k=1}^{n} \frac{1}{k} E\left[S_{k}^{+}\right] .
$$

Therefore,

$$
\begin{aligned}
& E\left[\max _{1 \leqq k \leqq n} S_{k}\right] \\
& \quad=\sum_{k=1}^{n} \frac{1}{k} E\left[S_{k}^{+}\right]-E\left(-S_{n}\right)-\sum_{k=1}^{n} \frac{1}{k} E\left[\left(S_{k}\right)^{+}\right]+\sum_{k=1}^{n-1} \frac{1}{k} E\left[\left(-S_{k}\right)^{+}\right] \\
& \quad=\sum_{k=1}^{n-1} \frac{1}{k} E\left[\left(-S_{k}\right)^{+}\right]-E\left(-S_{n}\right) \\
& \quad=E\left(S_{n}\right)+\sum_{k=1}^{n-1} \frac{1}{k} E\left[\left(-S_{k}\right)^{+}\right] .
\end{aligned}
$$

THEOREM 3.

(3.13) $E\left[\min _{1 \leqq k \leqq n} S_{k}\right]=E\left(S_{n}\right)-\sum_{k=1}^{n-1} \frac{1}{k} E\left(S_{k}^{+}\right)=E\left(S_{n}\right)-E\left[\max _{1 \leqq k \leqq n-1} S_{k}^{+}\right]$.

Proof.

(3.14) $\min _{1 \leqq k \leqq n} S_{k}=\min _{1 \leqq k \leqq n} S_{k}^{+}+\min _{1 \leqq k \leqq n} S_{k}^{-}$, and $\min _{1 \leqq k \leqq n} S_{\vec{k}}^{-}=-\max _{1 \leqq k \leqq n}\left(-S_{k}\right)^{+}$.

Therefore,

$$
\begin{aligned}
E\left[\min _{1 \leqq k \leqq n} S_{k}\right]= & E\left[\min _{1 \leqq k \leqq n} S_{k}^{+}\right]-E\left[\max _{1 \leqq k \leqq n}\left(-S_{k}\right)^{+}\right] \\
= & E\left(S_{n}\right)+\sum_{k=1}^{n} \frac{1}{k} E\left[\left(-S_{k}\right)^{+}\right]-\sum_{k=1}^{n-1} \frac{1}{k} E\left(S_{k}^{+}\right) \\
& -\sum_{k=1}^{n} \frac{1}{k} E\left[\left(-S_{k}\right)^{+}\right] \\
= & E\left(S_{n}\right)-\sum_{k=1}^{n-1} \frac{1}{k} E\left(S_{k}^{+}\right)=E\left(S_{n}\right)-E\left[\max _{1 \leqq k \leqq n-1} S_{k}^{+}\right] .
\end{aligned}
$$

4. Application to standard normal random variables. If $X_{1}$, 
$X_{2}, \cdots, X_{n}$ are standard normal random variables, then

$$
\begin{aligned}
& E\left[\max _{1 \leqq k \leqq n} S_{k}^{+}\right]=\frac{1}{\sqrt{2 \pi}} \sum_{k=1}^{n} \frac{1}{\sqrt{k}} \\
& E\left[\min _{1 \leqq k \leqq n} S_{k}^{+}\right]=\frac{1}{\sqrt{2 \pi n}} \\
& E\left[\operatorname{man}_{1 \leqq k \leqq n} S_{k}\right]=\frac{1}{\sqrt{2 \pi}} \sum_{k=1}^{n-1} \frac{1}{\sqrt{k}} \\
& E\left[\min _{1 \leqq k \leqq n} S_{k}\right]=-\frac{1}{\sqrt{2 \pi}} \sum_{k=1}^{n-1} \frac{1}{\sqrt{k}} .
\end{aligned}
$$

Statement (4.1) was proved by J. A. McFadden and J. L. Lewis in [1]. They applied F. Spitzer's lemma (Lemma 2) to the fact that for standard normal random variables,

$$
E\left(S_{k}^{+}\right)=\sqrt{\frac{k}{2 \pi}}
$$

To obtain (4.2), (4.3), and (4.4), apply (4.5) and the fact that for standard normal random variables, $E\left(S_{k}^{+}\right)=E\left[\left(-S_{k}\right)^{+}\right]$, to Theorems 1,2 , and 3 respectively.

\section{REFERENCES}

1. J. A. McFadden and J. L, Lewis, Multivariate normal integrals for highly correlated samples from a Wiener process, J. of Applied Probability, 4 (1967), 303-312.

2. F. Spitzer, A combrnatorial lemma and its application to probability theory, Trans. Amer. Math. Soc., 82, 323-339.

Received February 21, 1973 and in revised form June 6, 1973. This research was supported in part by the Faculty Research Award Program of The City University of New York under grant No. 1322.

Queens College of The City University of New York. 



\section{PACIFIC JOURNAL OF MATHEMATICS}

EDITORS

RICHARD ARens (Managing Editor)

University of California

Los Angeles, California 90024

\section{R. A. Beaumont}

University of Washington

Seattle. Washington 98105

\section{J. DugundjI}

Department of Mathematics University of Southern California Los Angeles, California 90007

D. Gilbarg and J. Milgram

Stanford University

Stanford. California 94305

\section{ASSOCIATE EDITORS}
E. F. BECKENBACH
B. H. NEUMANN
F. WOLF
K. Yoshida

\section{SUPPORTING INSTITUTIONS}

\author{
UNIVERSITY OF BRITISH COLUMBIA \\ CALIFORNIA INSTITUTE OF TECHNOLOGY \\ UNIVERSITY OF CALIFORNIA \\ MONTANA STATE UNIVERSITY \\ UNIVERSITY OF NEVADA \\ NEW MEXICO STATE UNIVERSITY \\ OREGON STATE UNIVERSITY \\ UNIVERSITY OF OREGON \\ OSAKA UNIVERSITY
}

\author{
UNIVERSITY OF SOUTHERN CALIFORNIA \\ STANFORD UNIVERSITY \\ UNIVERSITY OF TOKYO \\ UNIVERSITY OF UTAH \\ WASHINGTON STATE UNIVERSITY \\ UNIVERSITY OF WASHINGTON

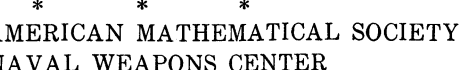

The Supporting Institutions listed above contribute to the cost of publication of this Journal, but they are not owners or publishers and have no responsibility for its content or policies.

Mathematical papers intended for publication in the Pacific Journal of Mathematics should be in typed form or offset-reproduced, (not dittoed), double spaced with large margins. Underline Greek letters in red, German in green, and script in blue. The first paragraph or two must be capable of being used separately as a synopsis of the entire paper. Items of the bibliography should not be cited there unless absolutely necessary, in which case they must be identified by author and Journal, rather than by item number. Manuscripts, in duplicate if possible, may be sent to any one of the four editors. Please classify according to the scheme of Math. Rev. Index to Vol. 39. All other communications to the editors should be addressed to the managing editor, or Elaine Barth, University of California, Los Angeles, California, 90024.

100 reprints are provided free for each article, only if page charges have been substantially paid Additional copies may be obtained at cost in multiples of 50 .

The Pacific of Journal Mathematics is issued monthly as of January 1966. Regular subscription rate: $\$ 72.00$ a year (6 Vols., 12 issues). Special rate: $\$ 36.00$ a year to individual members of supporting institutions.

Subscriptions, orders for back numbers, and changes of address should be sent to Pacific Journal of Mathematics, 103 Highland Boulevard, Berkeley, California, 94708.

\section{PUBLISHED BY PACIFIC JOURNAL OF MATHEMATICS, A NON-PROFIT CORPORATION}

Printed at Kokusai Bunken Insatsusha (International Academic Printing Co., Ltd.), 270, 3-chome Totsuka-cho. Shinjuku-ku, Tokyo 160. Japan.

Copyright (C) 1973 by Pacific Journal of Mathematics Manufactured and first issued in Japan 


\section{Pacific Journal of Mathematics}

\section{Vol. 52, No. $2 \quad$ February, 1974}

Harm Bart, Spectral properties of locally holomorphic vector-valued functions .....

J. Adrian (John) Bondy and Robert Louis Hemminger, Reconstructing infinite

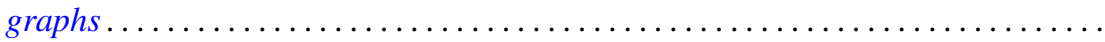

Bryan Edmund Cain and Richard J. Tondra, Biholomorphic approximation of planar

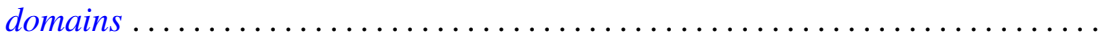

Richard Carey and Joel David Pincus, Eigenvalues of seminormal operators,

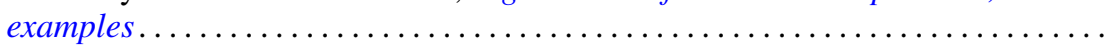

Tyrone Duncan, Absolute continuity for abstract Wiener spaces . . . . . . . . . . . . Joe Wayne Fisher and Louis Halle Rowen, An embedding of semiprime

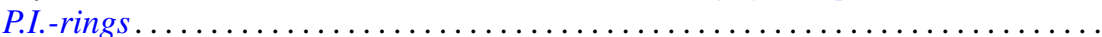

Andrew S. Geue, Precompact and collectively semi-precompact sets of semi-precompact continuous linear operators. . . . . . . . . . . . . . . .

Charles Lemuel Hagopian, Locally homeomorphic $\lambda$ connected plane continua ..... . Darald Joe Hartfiel, A study of convex sets of stochastic matrices induced by

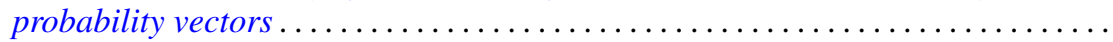

Yasunori Ishibashi, Some remarks on high order derivations $\ldots \ldots \ldots \ldots \ldots \ldots \ldots$ Donald Gordon James, Orthogonal groups of dyadic unimodular quadratic forms.

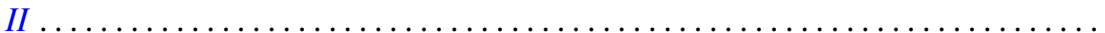

Geoffrey Thomas Jones, Projective pseudo-complemented semilattices . . . . . . . . . Darrell Conley Kent, Kelly Denis McKennon, G. Richardson and M. Schroder,

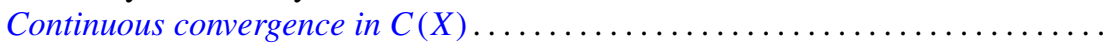

J. J. Koliha, Some convergence theorems in Banach algebras ...

Tsang Hai Kuo, Projections in the spaces of bounded linear oper

George Berry Leeman, Jr., A local estimate for typically real functions . .

475

Andrew Guy Markoe, A characterization of normal analytic spaces by the

homological codimension of the structure sheaf .........

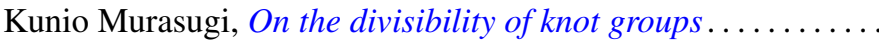

John Phillips, Perturbations of type I von Neumann algebras.

Billy E. Rhoades, Commutants of some quasi-Hausdorff matrices . .

David W. Roeder, Category theory applied to Pontryagin duality

Maxwell Alexander Rosenlicht, The nonminimality of the differential closure .

Peter Michael Rosenthal, On an inversion theorem for the general Mehler-Fock transform pair.

Alan Saleski, Stopping times for Bernoulli automorphisms

John Herman Scheuneman, Fundamental groups of compact complete locally affine complex surfaces. II. ........................

Vashishtha Narayan Singh, Reproducing kernels and operators with a cyclic vector. I. .

Peggy Strait, On the maximum and minimum of partial sums of random variables.

J. L. Brenner, Maximal ideals in the near ring of polynomials modulo 2 .

Ernst Gabor Straus, Remark on the preceding paper: "Ideals in near rings of polynomials over a field" ..........................

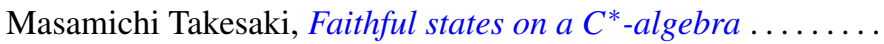

R. Michael Tanner, Some content maximizing properties of the regular simplex.

Andrew Bao-hwa Wang, An analogue of the Paley-Wiener theorem for certain

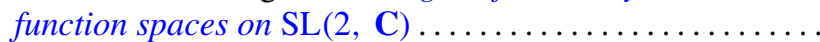

